of disease of the brain, the evidence of disease in the pituitary and its environs, headache and amaurosis, the ocular manifestations of injuries to the head and toxic substances which affect vision are also subjects which are discussed in detail. The text reveals an intimate knowledge of the purely medical aspects of the subject being discussed and is rendered more interesting and instructive by many case records.

The publishers have also to be congratulated on their share in the work. The type is pleasing and the reproductions of the illustrations, particularly so. The coloured plates, of which there are twenty, are excellent and will be found of the greatest assistance to students and physicians wishing to gain acquaintance with fundal and other changes in the eye. So valuable do we consider the illustrations that we regret that the frequent references to them in the text are usually by number alone, the page seldom being indicated. In consequence much time is lost and we respectfully suggest that in the second edition this omission be remedied.

\section{CLINICAL CHEMISTRY IN PRACTICAL MEDICINE. (Second Edition).}

By C. P. Stewart and D. M. Dunlop. E. \& S. Livingstone. 1937. Price 10s. 6d. net.

This is a book to be highly recommended and which should be the personal possession of all senior medical students and hospital residents.

The work is divided into two parts. The first and larger portion is concerned with a reasoned and philosophical account of the various directions in which the laboratory may render aid in the diagnosis and understanding of disease with details regarding the conditions which must be observed in the collection of the specimens by the clinician for the examination by the biochemist. The rationale of the various tests is described and their relative value is summed up. The basal metabolic rate, the acid-base balance of the body fluids, renal function, hepatic function, pancreatic function, the cerebro-spinal fluid, blood, urine and stomach contents all come under review.
The second portion of the work, classi- $\frac{\mathbb{Q}}{\mathrm{Q}}$ fied under various appendices, gives details $\stackrel{2}{L}$ of the technique of carrying out those investigations which the student or hospital $\stackrel{\vec{D}}{\mathrm{D}}$ resident should be able to perform for $\bar{c}$ himself.

As is so essential in a work of its kind a very full index is supplied.

\section{MODERN DISCOVERIES IN MEDICAL PSYCHOLOGY.}

By Clifford Allen. MacMillan \& Co. London. 1938. Price 8s. 6d.

Books on medical psychology appear in 3 ever increasing numbers, many being of $\overrightarrow{\vec{A}}$ little value to layman, student, practitioner or specialist. Dr. Allen, however, has managed to give a clear and interesting $\dot{\omega}$ exposition of the views held and taught by $\&$ some of those who have influenced modern 9 ideas about psychopathology.

Starting with Mesmer, he moves on to $\mathscr{D}$ Janet and Morton Prince, then after discussing Freud, Jung and Adler he ends with Kretschner and Pavlov. Short remarks about their personal history add to thê interest.

The presentation of so much material one short book is bound to be at times dogmatic and superficial as the author admits, but there is a short bibliography at the end of each chapter to enable the reader to widen his knowledge. The claim made in the introduction that the views expressed are impartial could hardly be upheld by anyone except a disciple of Freud. Each person discussed is praised or criticised according to whether his views support or are detrimental to those of Freud and it is implied that those who do not consider him omnipotent must be either oldfashioned or blinded by prejudice. This is a pity at a time when the views of the psychoanalytical school are assuming their proper proportions and Freud is accepted as a star in the psychiatric firmament, but not as the sun before which all others pale and disappear.

The lucidity of language and simplicity of the explanations are the main virtues of this book which should be of real value to those who are confused by the multiplicity of complicated theories expounded by the various schools of thought and desire a straightforward comprehensible presentation in order to clarify their minds. 